\title{
The changing face of major trauma in the UK
}

\author{
A Kehoe, ${ }^{1,2}$ J E Smith, ${ }^{1,2,3}$ A Edwards, ${ }^{4}$ D Yates, ${ }^{4}$ F Lecky ${ }^{4,5}$
}

(6)

\section{OPEN ACCESS}

${ }^{1}$ Emergency Department, Derriford Hospital, Plymouth UK

${ }^{2}$ Centre for Clinical Trials and Population Studies, Plymouth University Peninsula Schools of Medicine and Dentistry, Plymouth, UK

${ }^{3}$ Academic Department of Military Emergency Medicine, Royal Centre for Defence Medicine (Research \& Academia), Medical Directorate, Birmingham, UK ${ }^{4}$ Trauma Audit Research Network (TARN), University of Manchester, Hope Hospital, Salford, UK

${ }^{5}$ EMRiS Group, Health Services Research Section, School of Health and Related Research, University of Sheffield, Sheffield, UK

\section{Correspondence to}

Dr Anthony Kehoe, Emergency Department, Derriford Hospital, Derriford Road, Plymouth PL6 8DH, UK; tony.kehoe@nhs.net

Received 27 July 2015 Revised 13 October 2015 Accepted 22 October 2015

\section{ABSTRACT}

Aim Major trauma (MT) has traditionally been viewed as a disease of young men caused by high-energy transfer mechanisms of injury, which has been reflected in the configuration of MT services. With ageing populations in Western societies, it is anticipated that the elderly will comprise an increasing proportion of the MT workload. The aim of this study was to describe changes in the demographics of MT in a developed Western health system over the last 20 years.

Methods The Trauma Audit Research Network (TARN) database was interrogated to identify all cases of MT (injury severity score $>15$ ) between 1990 and the end of 2013. Age at presentation, gender, mechanism of injury and use of $\mathrm{CT}$ were recorded. For convenience, cases were categorised by age groups of 25 years and by common mechanisms of injury. Longitudinal changes each year were recorded.

Results Profound changes in the demographics of recorded MT were observed. In 1990, the mean age of MT patients within the TARN database was 36.1, the largest age group suffering MT was 0-24 years (39.3\%), the most common causative mechanism was road traffic collision (59.1\%), $72.7 \%$ were male and $33.6 \%$ underwent CT. By 2013, mean age had increased to 53.8 years, the single largest age group was 25 50 years $(27.1 \%)$, closely followed by those $>75$ years $(26.9 \%)$, the most common mechanism was low falls (39.1\%), $68.3 \%$ were male and $86.8 \%$ underwent CT. Conclusions This study suggests that the MT population identified in the UK is becoming more elderly, and the predominant mechanism that precipitates MT is a fall from $<2 \mathrm{~m}$. Significant improvements in outcomes from MT may be expected if services targeting the specific needs of the elderly are developed within MT centres.

\section{INTRODUCTION}

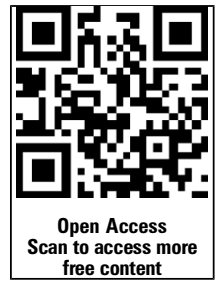

CrossMark

To cite: Kehoe A, Smith JE, Edwards A, et al. Emerg Med J 2015:32:911-915.
Major trauma is the leading cause of death and disability in those under 40 years old. ${ }^{1}$ It has been traditionally viewed as a disease of the young, with, in particular, young males involved in motor vehicle collisions and interpersonal violence making up the largest cohort of patients. Training for those involved in the management of patients suffering trauma has often concentrated on these aspects of injury. ${ }^{2}$

Major trauma in elderly patients is becoming increasingly recognised as a significant challenge to health systems. ${ }^{3}$ In many countries, the elderly comprise the most rapidly expanding section of the population. Advances in medical care mean that many enjoy better health, mobility and independence longer than ever before, increasing their exposure to the possibility of injury. Frailty is also a factor; the likelihood of falls increases with age as
Key messages

What is already known on this subject?

- Major trauma is traditionally considered to be a problem of young men.

- With ageing populations, it is predicted that in the future the elderly will comprise an increasingly significant proportion of the major trauma workload.

\section{What might this study add?}

- The future is here already - in the UK, the average age of major trauma cases on the Trauma Audit Research Network database in 2013 was nearly 60 years.

- Within the next few years, the over $75 \mathrm{~s}$ will be the single largest group suffering major trauma.

- The predominant mechanism of injury causing major trauma is no longer road traffic collision but low falls.

- The specific needs of the elderly must be considered in the design of major trauma services.

does the probability of significant injury as a consequence, while physiological reserve and the ability to recover is diminished. ${ }^{4}$

Meanwhile, detection and reporting of major trauma in elderly patients may be improving. More widespread use of whole-body $\mathrm{CT}^{5}$ allows the identification of previously occult injury in the elderly and national regulatory bodies increasingly demand more thorough recording of injury by institutions in national trauma registries. ${ }^{6}$

Major trauma can be defined in several different ways. The most widely adopted definition employs the injury severity score (ISS). An ISS of $\geq 16$ is the threshold defining major trauma. ${ }^{7}$ The ISS is calculated from the sum of the squares of the highest abbreviated injury scale (AIS) codes in the three most severely injured body regions. ${ }^{8}$ The AIS is scored from 1 to 6 , with 1 being a relatively trivial injury such as skin laceration, 5 being a critical injury such as an extradural haematoma with midline shift and 6 being regarded as an unsurvivable injury. The threshold of ISS $>15$ can be achieved either through a combination of lesser injuries to multiple body regions (eg, $2^{2}+2^{2}+3^{2}=$ ISS 17) or through one more severe injury to a single region (eg, $4^{2}=$ ISS 16 ).

The aim of this study was to describe changes in the demographics of patients suffering major trauma over two decades in a developed Western health system by interrogating a national trauma 
database. A better understanding of the true demographics of major trauma may help to shape the development of major trauma systems and facilities to ensure that the needs of the entire spectrum of patients suffering trauma can be met.

\section{METHODS}

The Trauma Audit Research Network (TARN) collects data on patients suffering trauma in England and Wales who are admitted to hospital for $\geq 72 \mathrm{~h}$, require critical care resources or who die from their injuries. Certain injuries, such as fractures of the pubic ramus or proximal femur in those aged $>65$ years, are specifically excluded. The TARN database was interrogated to identify a continuous cohort of all patients with major trauma defined as ISS $>15$ from 1990 to the end of 2013. Data included age, gender, mechanism of injury and the use of CT.

For each year, median (SD) age, gender frequency and percentage of cases undergoing CT investigation were calculated. Cases were categorised by age at time of injury into four groups (0-24 years, 25-49 years, 50-74 years and 75 years plus) and according to mechanism of injury, using the five most common categories of road traffic collision (RTC), falls from height $>2 \mathrm{~m}$, fall from height $<2 \mathrm{~m}$, shooting/stabbing combined and all others.

We also interrogated national hospital episode statistics (HES) data from 2005 onwards to give an indication of absolute numbers (rather than proportions) of patients with severe injury presenting to UK hospitals (figure 1).

\section{RESULTS}

During the study period, 116467 cases of major trauma were identified whose data are presented in tables 1 and 2 .

In 1990, the mean age of recorded patients suffering major trauma was 36.1 years, with the largest single group being those under 25 years (39.3\%). The over 75 s made up just $8.1 \%$ of the recorded major trauma population. Throughout the study period, mean age increased slowly from 1990 until 2006 at which point an accelerated increase was observed reaching 53.8 years by 2013 . By the end of the study period, those under 25 years comprised the smallest age group representing only $17 \%$ of major trauma cases, whereas a threefold increase in the proportion of over $75 \mathrm{~s}$ to $26.9 \%$ was observed. More modest increases and decreases were observed in the proportions of 50-74 and 25-49 year olds, respectively.

The proportion of men in the major trauma population did not vary dramatically, reducing slightly to $68 \%$ in 2013 from a peak of $75.5 \%$ in 2001 .

The mechanisms of injury causing major trauma in the TARN database also changed throughout the study period, tracking the changes in age groups. In 1990, the predominant mechanism was RTC, which was responsible for nearly $60 \%$ of all recorded major trauma while low falls comprised only 4.7\%. Through

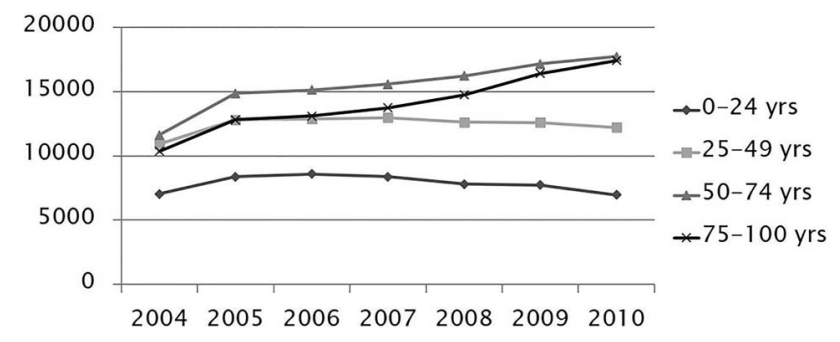

Figure 1 Hospital episode statistics data of patients eligible for Trauma Audit Research Network inclusion. the study period, the ratio of RTC:low fall changed dramatically, so that by 2013 low falls were responsible for $39.1 \%$ of cases and were the most common mechanism of injury causing major trauma in the UK while the proportion of major trauma from RTC had halved to just under 30\%. The proportions of high falls, shooting/stabbing and major trauma from all other causes remained relatively static throughout the study period.

\section{DISCUSSION}

This study demonstrates a rapid and profound change in the demographics of major trauma recorded in a developed health system over the last 20 years. It suggests that the true incidence of major trauma in the elderly greatly exceeds earlier predictions. Rather than being a disease of young men, the majority of patients suffering major trauma identified in the UK are now older than 50 years of age.

An increase in elderly trauma has been anticipated as the global population ages; indeed in 1990, MacKenzie predicted that by $2050,39 \%$ of trauma admission episodes in the USA would occur in those older than 65 years. ${ }^{9}$ From our data, if current trends persist, within the next few years those over 75 years of age will comprise the single largest group of patients suffering major trauma. Over the last 10 years, the average age of recorded patients suffering major trauma has increased at 1.43 years per year. This is nearly twice the annual yearly increase reported in a comparable Western European Trauma system in the previous decade. ${ }^{10}$

In 1990 , the overwhelming majority (60\%) of recorded major trauma was caused by RTCs. This proportion has now halved to $30 \%$ and has been comfortably overtaken by low-energy falls, which are now responsible for the highest proportion of patients suffering major trauma at $39 \%$.

There have been few previous UK studies investigating this issue. Giannoudis recently described trauma in the elderly in Leeds between 1997 and 2002. Here, patients over 65 years made up only $13.8 \%$ of the major trauma population and there was a clear peak in incidence in the early 20 s with a continuous decline thereafter with increasing age. The predominant mechanism of injury in this study was RTC, followed by falls $>2 \mathrm{~m}$, and then falls $<2 \mathrm{~m}^{11}$

There are numerous possible explanations for our observations. Data from the National Office for Statistics confirm that here has indeed been a dramatic reduction in death and serious injury resulting from RTC over the last 20 years. This is likely to have occurred due to a combination of improvements in car and road design, more effective regulation of speed, better safety and accident prevention education for the young. Another possible explanation is that there has been an increase in the absolute numbers of elderly patients suffering injury. Our analysis of HES data for hospital admissions with injury codes that would be eligible for TARN submission suggests that during a 6-year period between 2004 and 2010 the numbers of injured patients below 50 years of age remained stable, while there were large increases in the 50-75 years and $75+$ years groups of 50\% and $75 \%$, respectively (figure 1). This would match a general increase in the numbers of older people within the population.

While these data confirm an increase in the numbers of elderly patients with traumatic injury being diagnosed and recorded, they do not reveal whether this is because more elderly patients are actually suffering injury or because the detection and reporting of injury in these groups has improved. Over recent years, many advances in the management of major trauma have been introduced. One example is the increased use of CT with the widespread adoption of imaging guidelines for 
Table 1 Age, gender and frequency of CT scan

\begin{tabular}{|c|c|c|c|c|c|c|c|c|}
\hline \multirow[b]{2}{*}{ Year } & \multirow[b]{2}{*}{ Total } & \multicolumn{5}{|l|}{ Age $n(\%)$} & \multirow{2}{*}{$\begin{array}{l}\text { Male } \\
\mathrm{n}(\%)\end{array}$} & \multirow{2}{*}{$\begin{array}{l}\text { CT scan } \\
\mathrm{n}(\%)\end{array}$} \\
\hline & & $0-24$ & $25-49$ & $50-75$ & $\geq 75$ & Mean (SD) & & \\
\hline 1990 & 619 & $243(39.3 \%)$ & $208(33.6 \%)$ & $118(19.1 \%)$ & $50(8.1 \%)$ & $36.1(22.2)$ & $450(72.7 \%)$ & $208(33.6 \%)$ \\
\hline 1991 & 1306 & $488(37.4 \%)$ & $450(34.5 \%)$ & $245(18.8 \%)$ & $123(9.4 \%)$ & $36.9(23.1)$ & $964(73.8 \%)$ & $458(35.1 \%)$ \\
\hline 1992 & 1488 & $518(34.8 \%)$ & $513(34.5 \%)$ & $330(22.2 \%)$ & 127 (8.5\%) & 38.1 (22.6) & $1080(72.6 \%)$ & $484(32.5 \%)$ \\
\hline 1993 & 1494 & 491 (32.9\%) & $516(34.5 \%)$ & $328(22 \%)$ & $159(10.6 \%)$ & $39.9(23.3)$ & $1066(71.4 \%)$ & $438(29.3 \%)$ \\
\hline 1994 & 2939 & 1071 (36.4\%) & 954 (32.5\%) & $631(21.5 \%)$ & $283(9.6 \%)$ & $38.3(23.4)$ & $2183(74.3 \%)$ & $851(29 \%)$ \\
\hline 1995 & 3650 & 1259 (34.5\%) & 1335 (36.6\%) & $760(20.8 \%)$ & $296(8.1 \%)$ & $37.6(22.4)$ & $2688(73.6 \%)$ & $1180(32.3 \%)$ \\
\hline 1996 & 3468 & $1373(39.6 \%)$ & $1138(32.8 \%)$ & $673(19.4 \%)$ & $284(8.2 \%)$ & $36.1(22.7)$ & $2592(74.7 \%)$ & $1144(33 \%)$ \\
\hline 1997 & 2949 & 972 (33\%) & 1099 (37.3\%) & $624(21.2 \%)$ & $254(8.6 \%)$ & $38.3(22.4)$ & 2178 (73.9\%) & $1083(36.7 \%)$ \\
\hline 1998 & 2753 & $900(32.7 \%)$ & 1059 (38.5\%) & 537 (19.5\%) & 257 (9.3\%) & $38.2(22.5)$ & $1998(72.6 \%)$ & 1127 (40.9\%) \\
\hline 1999 & 3040 & 1004 (33\%) & 1111 (36.5\%) & $638(21 \%)$ & $287(9.4 \%)$ & $38.5(23)$ & $2220(73 \%)$ & $1455(47.9 \%)$ \\
\hline 2000 & 3215 & 1009 (31.4\%) & 1220 (37.9\%) & $732(22.8 \%)$ & $254(7.9 \%)$ & $39(22.1)$ & 2406 (74.8\%) & $1709(53.2 \%)$ \\
\hline 2001 & 3055 & 1047 (34.3\%) & $1138(37.3 \%)$ & $611(20 \%)$ & $259(8.5 \%)$ & $38.2(22.1)$ & $2306(75.5 \%)$ & $1717(56.2 \%)$ \\
\hline 2002 & 3221 & 1047 (32.5\%) & $1205(37.4 \%)$ & 687 (21.3\%) & $282(8.8 \%)$ & $39(22.2)$ & $2389(74.2 \%)$ & $1844(57.2 \%)$ \\
\hline 2003 & 3565 & $1164(32.7 \%)$ & $1354(38 \%)$ & $771(21.6 \%)$ & $276(7.7 \%)$ & $38.8(21.6)$ & $2640(74.1 \%)$ & $2031(57 \%)$ \\
\hline 2004 & 3358 & 1077 (32.1\%) & $1265(37.7 \%)$ & $718(21.4 \%)$ & $298(8.9 \%)$ & $39.5(22)$ & $2489(74.1 \%)$ & $1973(58.8 \%)$ \\
\hline 2005 & 3233 & 999 (30.9\%) & $1160(35.9 \%)$ & 765 (23.7\%) & 309 (9.6\%) & $40.6(22.4)$ & $2393(74 \%)$ & $1989(61.5 \%)$ \\
\hline 2006 & 2976 & $912(30.6 \%)$ & $1142(38.4 \%)$ & $663(22.3 \%)$ & $259(8.7 \%)$ & $40.2(21.7)$ & $2249(75.6 \%)$ & $1970(66.2 \%)$ \\
\hline 2007 & 4117 & $1143(27.8 \%)$ & 1573 (38.2\%) & 965 (23.4\%) & $436(10.6 \%)$ & $42(22.3)$ & 3061 (74.4\%) & $3024(73.5 \%)$ \\
\hline 2008 & 4691 & $1288(27.5 \%)$ & $1652(35.2 \%)$ & $1161(24.7 \%)$ & $590(12.6 \%)$ & $43.4(22.9)$ & $3443(73.4 \%)$ & $3606(76.9 \%)$ \\
\hline 2009 & 6701 & $1651(24.6 \%)$ & $2327(34.7 \%)$ & $1761(26.3 \%)$ & $962(14.4 \%)$ & $45.6(23.1)$ & $4922(73.5 \%)$ & $5415(80.8 \%)$ \\
\hline 2010 & 9583 & $2162(22.6 \%)$ & $3065(32 \%)$ & $2651(27.7 \%)$ & $1705(17.8 \%)$ & $47.7(24.4)$ & $6773(70.7 \%)$ & $7975(83.2 \%)$ \\
\hline 2011 & 12719 & $2720(21.4 \%)$ & $4073(32 \%)$ & $3373(26.5 \%)$ & $2553(20.1 \%)$ & $48.9(24.6)$ & $8959(70.4 \%)$ & $10790(84.8 \%)$ \\
\hline 2012 & 15089 & $2834(18.8 \%)$ & $4319(28.6 \%)$ & $4282(28.4 \%)$ & $3654(24.2 \%)$ & $51.8(25)$ & $10347(68.6 \%)$ & $13044(86.4 \%)$ \\
\hline 2013 & 17238 & 2933 (17\%) & 4665 (27.1\%) & 4999 (29\%) & 4641 (26.9\%) & 53.8 (25.2) & 11778 (68.3\%) & $14963(86.8 \%)$ \\
\hline
\end{tabular}

Table 2 Mechanism of injury

\begin{tabular}{|c|c|c|c|c|c|c|}
\hline \multirow[b]{2}{*}{ Year } & \multirow[b]{2}{*}{ Total } & \multicolumn{5}{|c|}{ Injury mechanism n (\%) } \\
\hline & & Road traffic collision & Fall $<2 \mathrm{~m}$ & Fall $>2 \mathrm{~m}$ & $\begin{array}{l}\text { Shooting/ } \\
\text { stabbing }\end{array}$ & Other \\
\hline 1990 & 619 & $366(59.1 \%)$ & $29(4.7 \%)$ & $115(18.6 \%)$ & $1(0.2 \%)$ & $108(17.4 \%)$ \\
\hline 1991 & 1306 & $775(59.3 \%)$ & $118(9 \%)$ & $211(16.2 \%)$ & $1(0.1 \%)$ & $201(15.4 \%)$ \\
\hline 1992 & 1488 & $900(60.5 \%)$ & $114(7.7 \%)$ & $229(15.4 \%)$ & - & $245(16.5 \%)$ \\
\hline 1993 & 1494 & $889(59.5 \%)$ & $150(10 \%)$ & $223(14.9 \%)$ & $3(0.2 \%)$ & $229(15.3 \%)$ \\
\hline 1994 & 2939 & $1691(57.5 \%)$ & $323(11 \%)$ & $405(13.8 \%)$ & $6(0.2 \%)$ & $514(17.5 \%)$ \\
\hline 1995 & 3650 & $2080(57 \%)$ & $385(10.5 \%)$ & $523(14.3 \%)$ & $20(0.5 \%)$ & $642(17.6 \%)$ \\
\hline 1996 & 3468 & $2012(58 \%)$ & $379(10.9 \%)$ & $514(14.8 \%)$ & $46(1.3 \%)$ & $517(14.9 \%)$ \\
\hline 1997 & 2949 & $1615(54.8 \%)$ & $339(11.5 \%)$ & $443(15 \%)$ & $58(2 \%)$ & $494(16.8 \%)$ \\
\hline 1998 & 2753 & $1507(54.7 \%)$ & $306(11.1 \%)$ & $432(15.7 \%)$ & $75(2.7 \%)$ & $433(15.7 \%)$ \\
\hline 1999 & 3040 & $1630(53.6 \%)$ & $373(12.3 \%)$ & $477(15.7 \%)$ & $94(3.1 \%)$ & $466(15.3 \%)$ \\
\hline 2000 & 3215 & $1666(51.8 \%)$ & $387(12 \%)$ & 537 (16.7\%) & $100(3.1 \%)$ & $525(16.3 \%)$ \\
\hline 2001 & 3055 & $1609(52.7 \%)$ & $330(10.8 \%)$ & 507 (16.6\%) & $132(4.3 \%)$ & $477(15.6 \%)$ \\
\hline 2002 & 3221 & $1738(54 \%)$ & 370 (11.5\%) & $513(15.9 \%)$ & $114(3.5 \%)$ & $486(15.1 \%)$ \\
\hline 2003 & 3565 & $1877(52.7 \%)$ & $435(12.2 \%)$ & $566(15.9 \%)$ & $133(3.7 \%)$ & $554(15.5 \%)$ \\
\hline 2004 & 3358 & $1710(50.9 \%)$ & $435(13 \%)$ & $558(16.6 \%)$ & $122(3.6 \%)$ & $533(15.9 \%)$ \\
\hline 2005 & 3233 & $1535(47.5 \%)$ & $487(15.1 \%)$ & $611(18.9 \%)$ & $117(3.6 \%)$ & $483(14.9 \%)$ \\
\hline 2006 & 2976 & $1440(48.4 \%)$ & 461 (15.5\%) & $538(18.1 \%)$ & $102(3.4 \%)$ & $435(14.6 \%)$ \\
\hline 2007 & 4117 & 1852 (45\%) & $751(18.2 \%)$ & $772(18.8 \%)$ & $105(2.6 \%)$ & $637(15.5 \%)$ \\
\hline 2008 & 4691 & $1937(41.3 \%)$ & $1002(21.4 \%)$ & $942(20.1 \%)$ & $138(2.9 \%)$ & $672(14.3 \%)$ \\
\hline 2009 & 6701 & 2580 (38.5\%) & $1646(24.6 \%)$ & $1321(19.7 \%)$ & $203(3 \%)$ & $951(14.2 \%)$ \\
\hline 2010 & 9583 & $3144(32.8 \%)$ & $2811(29.3 \%)$ & 2007 (20.9\%) & $248(2.6 \%)$ & $1373(14.3 \%)$ \\
\hline 2011 & 12719 & $4115(32.4 \%)$ & $4194(33 \%)$ & $2299(18.1 \%)$ & $323(2.5 \%)$ & $1788(14.1 \%)$ \\
\hline 2012 & 15089 & $4747(31.5 \%)$ & $5458(36.2 \%)$ & 2715 (18\%) & $342(2.3 \%)$ & $1827(12.1 \%)$ \\
\hline 2013 & 17238 & $5093(29.5 \%)$ & $6737(39.1 \%)$ & $3106(18 \%)$ & $328(1.9 \%)$ & $1974(11.5 \%)$ \\
\hline
\end{tabular}


head injury and the increased use of whole-body CT (or pan CT) as the investigation of choice in polytrauma. ${ }^{5}$ This allows the early detection of injuries that previously may have remained undetected or undefined. As an example, an elderly patient with an intracerebral contusion, two fractured ribs and a wedge fracture of a lumbar vertebra would have an ISS of $17\left(3^{2}+2^{2}+2^{2}\right)$ and would be classified as a patient suffering major trauma. Without the use of CT, such injuries may well have gone undetected in the past. Further work is required to determine whether or not this truly represents a burgeoning epidemic of elderly trauma.

The challenges of this new trauma landscape are wide ranging. Field triage tools that use a combination of mechanism of injury, vital signs and identifiable anatomical injury are likely to be less sensitive in identifying major trauma in the elderly. In a recent multicentre study from the West Coast of America, Nakamura $e$ t $a l^{12}$ reported a progressive decrease in the sensitivity of field triage guidelines with each decade of life beyond 60 years. In a UK major trauma centre (MTC) serving a population with a high proportion of elderly patients, the overall sensitivity of the local field triage tool for identifying major trauma was estimated to be as low as $52 \% .^{13}$

The pathophysiological response to trauma in the elderly is different to the young. ${ }^{414}$ In particular, emerging evidence suggests that for a given anatomical severity of traumatic brain injury the impairment in GCS in the elderly is less than that in the young. ${ }^{15} 16$ The state of Ohio was among the first to introduce evidence-based geriatric-specific guidelines for the over $70 \mathrm{~s},{ }^{17}$ the most significant modification of which is elevating the GCS threshold from 13 to $14 .{ }^{18}$ Compared with standard adult criteria, these new guidelines have increased the sensitivity of triage in elderly patients suffering major trauma from $61 \%$ to $93 \%$ with a corresponding modest decrease in specificity from $61 \%$ to $49 \% .^{19}$

For similar reasons, having arrived at hospital, activating the right trauma team response for elderly fallers is difficult. In many systems, trauma team activation criteria closely resemble field triage tools. Activating a hospital-wide trauma response for every elderly patient injured in a low fall would be disruptive and impractical, but a tiered trauma response may allow early senior clinician assessment with rapid access to advanced diagnostics for elderly fallers ${ }^{20}$ and some institutions have extended their activation criteria to include elderly patients with head or torso injury from low falls. ${ }^{21}$

Significant comorbidity is more likely in older patients. Mortality in elderly patients suffering major trauma is much higher than that in their younger counterparts, ${ }^{22}{ }^{23}$ but with appropriately configured services good outcomes can be achieved. ${ }^{3} 2425$ For many elderly patients suffering trauma undergoing non-operative management, targeted rehabilitation on a dedicated trauma unit may yield similar mortality benefits to those observed in orthopaedic trauma units with embedded orthogeriatric services. ${ }^{26}$ Identification and early aggressive management of patients at higher risk of developing complications such as those with blunt chest wall trauma ${ }^{27}$ may improve mortality and morbidity while reducing hospital stay.

\section{LIMITATIONS}

Our study has several important limitations inherent in the design of retrospective database analyses. In particular, the inconsistency in institutions submitting data to TARN over the last 20 years means it is difficult to be certain that the effect observed is not simply due to incomplete data collection. Since the advent of regional major trauma networks in England around
2012, many more institutions submit data to TARN. Data recorded from this point are, therefore, more likely to offer a true reflection of the national trauma caseload. While not directly comparable, national HES data are more comprehensive and show the absolute numbers of patients in each age range receiving an International Statistical Classification of Diseases and Related Health Problems, tenth revision code indicating traumatic injury that would be potentially eligible for inclusion in the TARN database. Although not all of these patients will meet the definition of major trauma, this would support the idea of a marked increase in the numbers of elderly patients suffering trauma diagnosed with injury, although this may still be explained at least partly by increased detection rather than a burgeoning epidemic of new cases. Our findings may be not be generalisable to other health systems with different population demographics or a higher incidence of penetrating trauma.

\section{CONCLUSIONS}

This study shows that the population in whom major trauma is identified and recorded is becoming more elderly, and the predominant mechanism that precipitates major trauma is a fall from $<2 \mathrm{~m}$. This is the first study to identify an apparently radical change in the demographics of major trauma in the UK over the last 20 years. Significant improvements in outcomes from trauma may be expected if trauma services targeting the specific needs of this patient group are developed within major trauma centres.

\section{Twitter Follow Antoinette Edwards at @AntoinetteE60}

Contributors AK and JES conceived the original idea. AE, DY and FL provided data and analysis. AK wrote the working draft and all authors contributed to editing the draft.

Competing interests None declared.

Ethics approval TARN holds HRA CAG section 251 approval for research on anonymised data submitted by member hospitals.

Provenance and peer review Not commissioned; externally peer reviewed.

Open Access This is an Open Access article distributed in accordance with the Creative Commons Attribution Non Commercial (CC BY-NC 4.0) license, which permits others to distribute, remix, adapt, build upon this work non-commercially, and license their derivative works on different terms, provided the original work is properly cited and the use is non-commercial. See: http://creativecommons.org/ licenses/by-nc/4.0/

\section{REFERENCES}

1 Krug EG, Sharma GK, Lozano R. The global burden of injuries. Am J Public Health 2000;90:523-6.

2 Collicott PE, Hughes I. Training in advanced trauma life support. JAMA 1980:243:1156-9.

3 Grossman MD, Ofurum U, Stehly CD, et al. Long-term survival after major trauma in geriatric trauma patients: the glass is half full. J Trauma Acute Care Surg 2012:72:1181-5.

4 Bruijns SR, Guly HR, Bouamra 0, et al. The value of traditional vital signs, shock index, and age-based markers in predicting trauma mortality. J Trauma Acute Care Surg 2013;74:1432-7.

5 Huber-Wagner $S$, Lefering $R$, Qvick LM, et al. Effect of whole-body CT during trauma resuscitation on survival: a retrospective, multicentre study. Lancet 2009;373:1455-61.

6 Lecky F, Woodford M, Edwards A, et al. Trauma scoring systems and databases. Br J Anaesth 2014;113:286-94.

7 Baker SP, O'Neill B, Haddon W Jr, et al. The injury severity score: a method for describing patients with multiple injuries and evaluating emergency care. J Trauma 1974;14:187-96.

8 AAAM, editor Committee on Injury Scaling. Injury Impairment Scale 1994; Des Plaines Association for the Advancement of Automotive Medicine.

9 MacKenzie EJ, Morris JA Jr, Smith GS, et al. Acute hospital costs of trauma in the United States: implications for regionalized systems of care. J Trauma 1990;30:1096-101; discussion 101-3.

10 Aldrian S, Nau T, Koenig F, et al. Geriatric polytrauma. Wien Klin Wochenschr 2005;117:145-9.

11 Giannoudis PV, Harwood PJ, Court-Brown C, et al. Severe and multiple trauma in older patients; incidence and mortality. Injury 2009;40:362-7. 
12 Nakamura $\mathrm{Y}$, Daya $\mathrm{M}$, Bulger $\mathrm{EM}$, et al. Evaluating age in the field triage of injured persons. Ann Emerg Med 2012;60:335-45.

13 Potter D, Kehoe A, Smith JE. The sensitivity of pre-hospital and in-hospital tools for the identification of major trauma patients presenting to a major trauma centre. $J R$ Nav Med Serv 2013;99:16-9.

14 Heffernan DS, Thakkar RK, Monaghan SF, et al. Normal presenting vital signs are unreliable in geriatric blunt trauma victims. J Trauma 2010;69:813-20.

15 Kehoe A, Rennie S, Smith JE. Glasgow Coma Scale is unreliable for the prediction of severe head injury in elderly trauma patients. Emerg Med J 2015;32:613-15.

16 Salottolo K, Levy AS, Slone DS, et al. The effect of age on Glasgow Coma Scale score in patients with traumatic brain injury. JAMA Surg 2014;149: 727-34.

17 Werman HA, Erskine T, Caterino J, et al. Members of the Trauma Committee of the State of Ohio EMSB. Development of statewide geriatric patients trauma triage criteria. Prehosp Disaster Med 2011;26:170-9.

18 Caterino JM, Raubenolt A, Cudnik MT. Modification of Glasgow Coma Scale criteria for injured elders. Acad Emerg Med 2011;18:1014-21.

19 Ichwan B, Darbha S, Shah MN, et al. Geriatric-specific triage criteria are more sensitive than standard adult criteria in identifying need for trauma center care in injured older adults. Ann Emerg Med. 2015;65:92-100.e3.
20 Jenkins $\mathrm{P}$, Rogers J, Kehoe $\mathrm{A}$, et al. An evaluation of the use of a two-tiered trauma team activation system in a UK major trauma centre. Emerg Med J 2015;32:364-7.

21 Spaniolas K, Cheng JD, Gestring ML, et al. Ground level falls are associated with significant mortality in elderly patients. J Trauma 2010;69:821-5.

22 Tornetta P III, Mostafavi H, Riina J, et al. Morbidity and mortality in elderly trauma patients. J Trauma 1999;46:702-6.

23 Ayoung-Chee $\mathrm{P}, \mathrm{McIntyre} L$, Ebel $\mathrm{BE}$, et al. Long-term outcomes of ground-level falls in the elderly. J Trauma Acute Care Surg 2014;76:498-503; discussion.

24 Wong GK, Graham CA, Ng E, et al. Neurological outcomes of neurosurgical operations for multiple trauma elderly patients in Hong Kong. J Emerg Trauma Shock 2011;4:346-50.

25 Lau D, El-Sayed AM, Ziewacz JE, et al. Postoperative outcomes following closed head injury and craniotomy for evacuation of hematoma in patients older than 80 years. J Neurosurg 2012;116:234-45.

26 Boddaert J, Cohen-Bittan J, Khiami F, et al. Postoperative admission to a dedicated geriatric unit decreases mortality in elderly patients with hip fracture. PLOS ONE 2014;9:e83795.

27 Battle C, Hutchings $\mathrm{H}$, Lovett $\mathrm{S}$, et al. Predicting outcomes after blunt chest wall trauma: development and external validation of a new prognostic model. Crit Care 2014;18:R98 